\title{
Competitive Unemployment Insurance Pricing
}

\author{
by Michael Beenstock*
}

\section{How special is unemployment insurance?}

In reviewing the literature on unemployment insurance Professor Malinvaud makes the standard assumption that unemployment insurance is a "special case" in the economics of insurance. He cites the problems of adverse selection, moral hazard, risk classification and difficulties in measuring the (dis)utility of unemployment to the insured. But these are general problems that are not peculiar to unemployment insurance and apply equally to property insurance, etc.

What is special about unemployment insurance, as Professor Malinvaud notes, is that on the whole, it is compulsory and it is operated by the state. For instance, in the U.K. National Insurance contributions (which buy entitlement to unemployment benefit) are both compulsory and flat rated. The latter implies that the premium that individuals pay do not fairly reflect the unemployment risks that are being underwritten. Some of us (e.g. tenured academics) face no unemployment risks yet we still have to buy insurance while others who face high unemployment risks must feel that they are under-insured under our present arrangements. Incidentally, this behaviour implies that unemployment insurance, as presently practiced, involves an element of redistribution that Professor Malinvaud did not mention. Because unemployment insurance premia are unlikely to be actuarially fair, those of us who are paying too much for our insurance are cross-subsidizing those of us who are paying premiums that are actuarially too low.

To be more constructive, however, I would like to suggest a theoretical basis for putting unemployment insurance on the same footing as other forms of insurance in which premia reflect the risks that are being underwritten. This scheme could be operated by the state or more probably it might be supplied more efficiently by the private sector as is the case with most forms of insurance. However, the scheme is not as revolutionary as it sounds because before the present political economy of unemployment insurance became established unemployment insurance was indeed supplied on this basis. See Beenstock and Brasse (1984, cap 2).

The basic premise is that individual premia should reflect the marginal cost of the unemployment contingent risks that are being underwritten. Alternatively, the premia

* Professor, City University Business School. 
should be competitively determined in the sense that the insurance companies supplying unemployment insurance contracts should not be able to earn arbitrage profits or monopolistic profits. This seems a sensible starting point in terms of welfare theory. However, it is stressed that welfare depends also on the sensible design of contracts noted by Professor Malinvaud.

\section{The contract}

Consider the case of a worker who pays his unemployment insurance premium at time $t=0$. This premium $(P)$ is a claim on a benefit flow $(B)$ per unit time period which is contingent upon him becoming unemployed. We shall assume that the policy allows

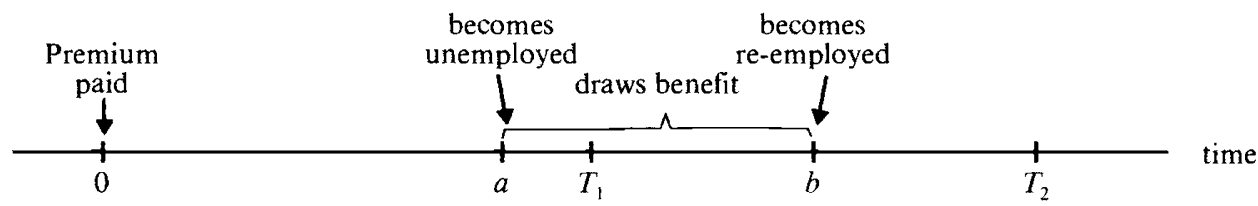

him to claim this benefit until he has found another job. In the above scheme he loses his job at time $a$ but finds another one at time $b$. The policy expires at $T_{1}$ in the sense that he can only claim on the policy if he becomes unemployed prior to $T_{1}$. The policy also stipulates that he cannot claim benefit beyond $T_{2}$. Naturally, $T_{2}$ must be greater than $T_{1}$ for the policy to serve any purpose. In the above scheme we have assumed that $T_{1}>a$ and $T_{2}>b$. Therefore the holder of the policy draws benefit over the period $a b$. If instead $T_{2}<b$ he only draws benefit over the period $a T_{2}$. Finally if $a>T_{1}$ he may draw no benefit at all.

Under the terms of the contract policy holders are not limited to one spell of unemployment. They can experience as many spells as may arise, however, they can only claim on the policy if the onset of spells begins prior to $T_{1}$. As suggested by Shavell and Weiss (1979) a more efficient contract design might relate the benefit to the duration of unemployment, or as Sampson (1979) suggests the benefits might also incorporate a lump sum payment received when the spell of unemployment begins. These features are designed to limit moral hazard. However, they are not robust enough with respect to assumptions about wealth, the distribution of jobs and so on. Therefore, the contract we consider may not be efficient but it will serve for our present purposes.

\section{The evolution of claimants}

At any moment in time (such as $t=0$ ) new policies are purchased by workers. We assume that the unemployment insurance market has identified various risk groups just as it does for car insurance, etc. The more refined the risk groups the smaller will be the problems of adverse selection. For each risk class we denote $\alpha_{j}$ as the probability of entering into unemployment and $\beta$ as the probability of exiting from unemployment for the cohort of policy holders as a whole. Therefore in contrast to $a$ and $b, \alpha$ and $\beta$ apply across the cohort as a whole rather than to specific individuals. We assume that the $\alpha s$ and $\beta s$ are independent across risk groups and are non-stochastic. If $L_{i}^{*}$ is the number of 
policy holders in the $j^{\prime}$ th risk class that enters the unemployment insurance market at $t=0$ the change in the number of claimants in the cohort will be

$$
\dot{u}_{j}=\alpha_{j} L_{j}-\beta_{j} u_{j}
$$

where $u$ is the number of unemployed in the cohort, $L$ is the number of employed and so

$$
L_{j}^{*}=L_{j}+u_{j}
$$

Equation (1) states that there are $\alpha_{j} L_{j}$ new claimants and $\beta_{j} u_{j}$ who cease to claim. The general solution to equation (1) is

$$
u_{j}(t)=\frac{\alpha_{i}}{\alpha_{j}+\bar{\beta}_{j}} L_{j}^{*}+A e^{-\left(\alpha_{j}+\beta_{j}\right) t}
$$

As $t$ tends to infinity the unemployment rate tends to $\frac{\alpha_{j}}{\alpha_{j}+\beta_{i}}$

At $t=0$ the number of claimants must be zero because only those with jobs are eligible hence

$$
u_{j}(t)=\frac{\alpha_{j} L_{j}^{*}}{\alpha_{j}+\beta_{j}}\left(1-e^{-\left(\alpha_{j}+\beta_{j}\right) t}\right)
$$

is the number of claimants in the cohort. In what follows we drop the $j$ subscripts because the principles are identical for each risk class and for all cohorts over time. Equation (3) implies that the growth rate of unemployment is positive but is declining, i.e.

$$
\begin{aligned}
\frac{\dot{u}}{u} & =\frac{\alpha+\beta}{e^{(\alpha+\beta) t}-1}>0 \\
\frac{d}{d t}\left(\frac{\dot{u}}{u}\right) & =\frac{-(\alpha+\beta)^{2} e^{(\alpha+\beta) t}}{\left(e^{(\alpha+\beta) t}-1\right)^{2}}<0
\end{aligned}
$$

The time profile of the stock of claimants (unemployed) that equation (3) implies is illustrated on Figure 1 by the schedule $0 a b$. Along the $0 a$ segment the growth rate is positive but declining. Beyond $T_{1}$ the growth rate is constant and negative and is equal to $-\beta$ since according to equation (2) after $T_{i} \dot{u}=-\beta u$.

Figure 1. The stock of claimants over time

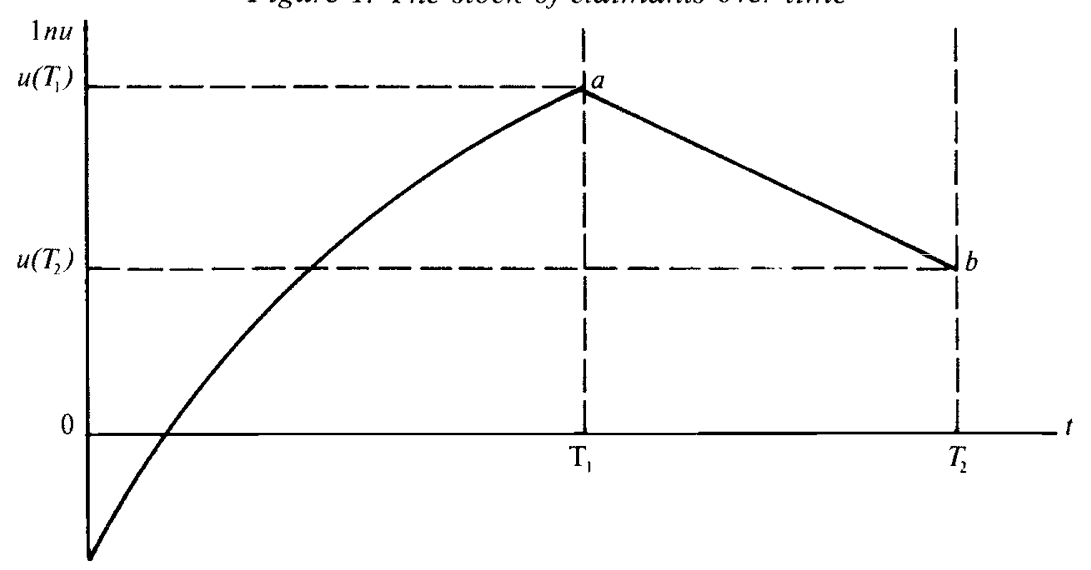




\section{Present value analysis}

The flow of claims is equal to the benefit rate multiplied by the number of claimants $B(t) u(t)$. Assuming for simplicity that the benefit rate moves in line with inflation equation (3) implies that the expected present value of the benefits (measured at $t=0$ ) to the cohort as a whole is ( $\rho$ is the discount rate)

$$
\begin{aligned}
X & =\int_{0}^{T_{1}} \frac{\alpha L^{*}}{\alpha+\beta}\left(1-e^{-(\alpha+\beta) t}\right) B e^{-\rho t} d t \\
& +\int_{T_{1}}^{T_{2}} \frac{\alpha L^{*}}{\alpha+\beta}\left(1-e^{-(\alpha+\beta) T_{1}}\right) e^{-\beta\left(t-T_{1}\right)} B e^{-\rho t} d t
\end{aligned}
$$

The first integral expresses the present value of claims up to $T_{1}$, i.e. it allows for new claimants and the associated flow of benefits. It also allows for claimants who go back into employment. The second integral expresses the present value of the claims generated by those who are still unemployed at the time the first element of the policy expires, i.e. at time $T_{1}$. At time $T_{1}$ equation (3) implies that the stock of claimants is

$$
u\left(T_{1}\right)=\frac{\alpha L^{*}}{\alpha+\beta}\left(1-e^{-(\alpha+\beta) 7_{1}}\right)
$$

but these cease to be claimants at the rate $\beta$. Evaluating the above integrals $X$ may be expressed as

$$
\begin{aligned}
X & =\frac{\alpha B L^{*}}{\rho(\alpha+\beta)(\beta+\rho)(\alpha+\beta+\rho)}\left[(\beta+\rho)(\alpha+\beta)-(\alpha+\beta+\rho) \beta e^{-\rho T_{1}}\right. \\
& \left.-\rho \alpha e^{-(\alpha+\beta+\rho) T_{1}}+\rho(\alpha+\beta+\rho)\left(e^{-\alpha T_{1}-(\beta+\rho) T_{2}}-e^{\beta\left(T_{1}-T_{2}\right)-\rho T_{2}}\right)\right]
\end{aligned}
$$

Since fair and competitive pricing implies that the expected present value of the benefits must equal premium income $\left(P L^{*}\right)$, i.e. the equilibrium condition is

$$
X=P L^{*}
$$

we may deduce that equilibrium premium is

$$
\begin{aligned}
P & =\frac{B \alpha}{\rho(\alpha+\beta)(\beta+\rho)(\alpha+\beta+\rho)}\left[(\beta+\rho)(\alpha+\beta)-(\alpha+\beta+\rho) e^{-\rho T_{1}}\right. \\
& \left.-\rho \alpha e^{-(\alpha+\beta+\rho) T_{1}}+\rho(\alpha+\beta+\rho)\left(e^{-\alpha T_{1}-(\beta+\rho) T_{2}}-e^{\left(T_{1}-T_{2}\right)-\rho T_{2}}\right)\right]
\end{aligned}
$$

This is the fundamental unemployment insurance pricing equation. Thus for each risk class $P$ depends on the real rate of interest, the two time limits in the policy and the inflow and outflow probabilities. As in the case of equation (1) the premium is proportionate to the benefits. $P$ will not be constant over time because in practice the parameters are likely to vary. For instance during the last few years the $\alpha \mathrm{s}$ have substantially risen and the $\beta$ s have substantially fallen across virtually all risk classes. However, these changes are unlikely to have affected each risk class to a proportionate extent. The $\alpha$ coefficients should be projected over the period $0-T_{1}$ and the $\beta$ coefficients should be projected over the period $0-T_{2}$. Therefore care should be taken in extrapolating past trends in the $\alpha \mathrm{s}$ and the $\beta \mathrm{s}$. Equation (4) is analogous to the property insurance pricing formula obtained by Kraus and Ross (1982). 


\section{Moral hazard}

$\alpha$ and $\beta$ will reflect numerous factors. Some of these factors will be specific to the individual, e.g. his state of health and previous employment experience. Some will be related to the market as a whole e.g. the general economic situation and the state of the labour market. $\alpha$ and $\beta$ will also reflect moral hazard. Once the individual is insured the temptation will be to get himself fired and once he has been fired there will be the further temptation of living on the policy rather than seeking re-employment. The former temptation will tend to raise $\alpha$ while the latter temptation will tend to lower $\beta$. Following Baily (1977) and Flemming (1979) we postulate that moral hazard varies directly with the replacement ratio. Hence :

$$
\left\{\begin{aligned}
\alpha & =\alpha_{0}+F(B / W) & & F^{\prime}>0 \\
\beta & =\beta_{0}+G(B / W) & & G^{\prime}<0
\end{aligned}\right.
$$

where $\alpha_{0}$ and $\beta_{0}$ are the values that $\alpha$ and $\beta$ take in the absence of moral hazard, and $W$ is the wage rate of the insured. Thus if $B$ is non-zero $\alpha>\alpha_{0}$ and $\beta<\beta_{0}$. In the absence of these effects the unit cost of insurance benefit $\left(P^{\prime}\right)$ is constant. In this case $P^{\prime}$ is simply the solution of equation (4) divided by $B$. But if $\alpha$ and $\beta$ vary with $B$ as suggested by equations (5) $P^{\prime}$ will rise with $B$ and fall with $W$. We shall return to this issue when we discuss Figure 2 below.

Equations (5) have a more general interpretation since apart from moral hazard policy holders might consciously decide to substitute leisure for work since benefits lower the opportunity cost of unemployment. Insofar as they do this $\alpha$ may rise and $\beta$ will fall. The main point, however, is that $P^{\prime}$ must rise for whatever reasons $\alpha$ and $\beta$ happen to vary because all risks must be "fairly" priced.

\section{Demand for insurance}

Although our central concern is with the supply of unemployment insurance some discussion of demand is necessary to determine the size of the unemployment insurance contract, i.e. how much benefit agents buy. We therefore postulate the simplest of two period models. In the first period the individual is at work earning a disposable wage of $W$ and paying out $P^{\prime} B$ to his unemployment insurance broker. In the second period he is either employed or unemployed. In the latter case his income is $\beta$ plus any social security $(S)$ to which he might be entitled. If the probability of employment in the second period is $\pi$ and the utility function of the individual is given by

$$
u=-e^{-b Y}
$$

where $Y$ denotes income, the present value of expected utility is

$$
E(u)=-e^{-h(W-B P)}-\pi e^{-h(H \cdot)}-(1-\pi) e^{-h(B+S) v)}
$$

where $\gamma=1 /(1+\rho)$ is a discount factor. The optimal quantity of cover is found by maximising $E(u)$ with respect to $B$. This exercise implies that the demand for insurance is given by the following equation :

$$
B=-\frac{\frac{\ln }{b}\left(\frac{P^{\prime}}{\gamma(1-\pi)}\right)+\gamma S-W}{P^{\prime}+\gamma}
$$


Since

$$
\frac{\partial B}{\partial P^{\prime}}=-\frac{\left(b P^{\prime}\right)^{-1}+B}{P^{\prime}+\gamma}
$$

we may deduce that the demand for cover is downward sloping provided that $B>-\left(b P^{\prime}\right)^{-1}$. We may also deduce that the demand function is convex since

$$
\frac{\partial^{2} B}{\partial P^{\prime 2}}=\frac{\left(P^{\prime}+\gamma\right)\left(\left(b P^{\prime}\right)^{-2}-\frac{\partial B}{\partial P^{\prime}}\right)+B+\left(b P^{\prime}\right)^{-1}}{\left(P^{\prime}+\gamma\right)^{2}}>0
$$

Equation (6) further implies that the demand for cover rises with the probability of unemployment since

$$
\frac{\partial B}{\partial(1-\pi)}=\frac{P^{\prime}+\gamma}{b(1-\pi)}>0
$$

and it implies that demand varies directly with the wage rate and inversely with social security benefits. Therefore the more the state provides "free" benefits the lower is the demand for competitive insurance. If $S$ is sufficiently high $B$ may be zero or even negative since in principle excessive insurance can be off-loaded in a competitive market.

\section{Supply and demand}

Figure 2 illustrates heuristically how supply and demand for unemployment insurance might be integrated. Equation (4) implies that the supply schedule is infinitely

Figure 2. Premium rates and premium income

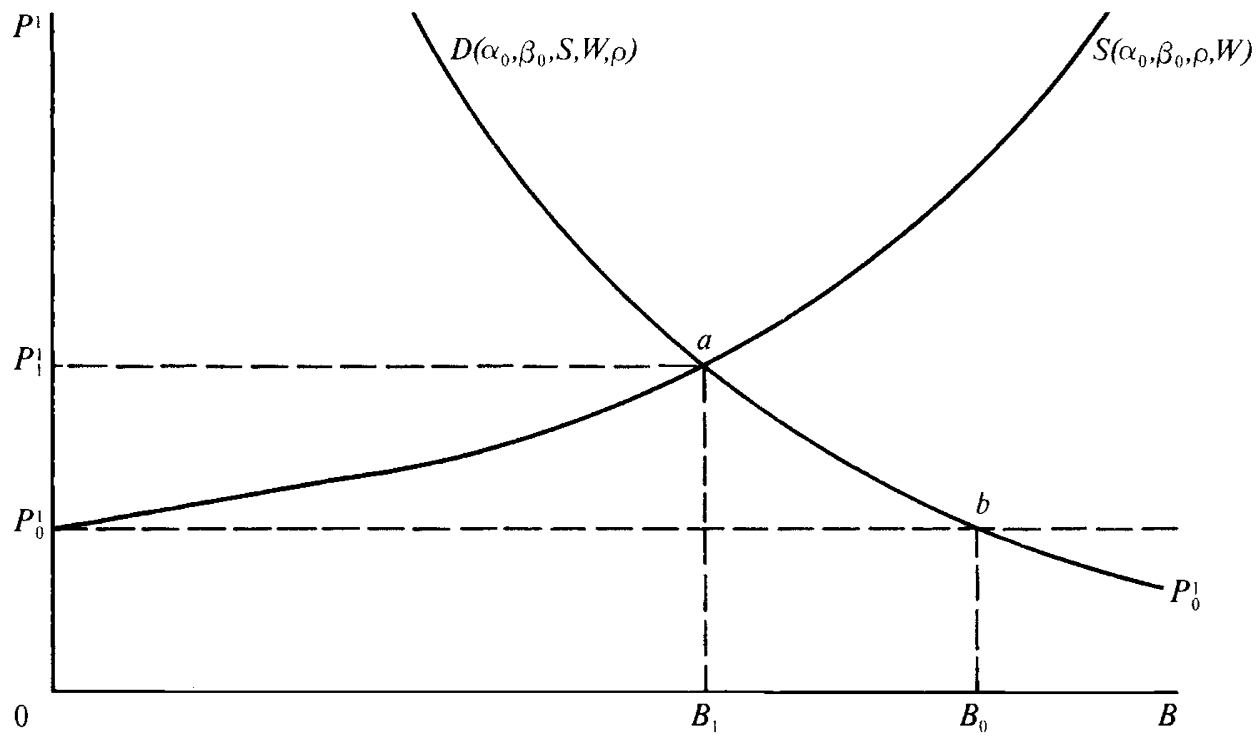


elastic at the premium rate $P_{0}^{\prime}$ which is generated by the equation when it is divided by $B$. Thus on Figure $2 P_{0}^{\prime} P_{0}^{\prime}$ represents this infinitely elastic schedule. More generally equations (5) suggest that the supply schedule will be upward sloping since unit costs rise with $B$. In this case the supply schedule may be represented by $P_{0}^{\prime} S$. As $\alpha_{0}$ and $\rho$ rise the supply schedule shifts to the left homothetically. It shifts to the right homothetically when $\beta_{0}$ rises. When $W$ rises it rotates to the right about the origin at $P_{0}^{\prime}$. The demand schedule is downward sloping as suggested by equation (6) and is convex to the origin. If, as Harris and Todaro (1970) suggest, the probability of unemployment may be represented by the unemployment rate equation (2) implies that

$$
1-\pi=\frac{\alpha_{0}}{\alpha_{0}+\beta_{0}}
$$

Therefore the demand schedule may be parameterised in terms of $\alpha_{0}$ and $\beta_{0}$ as indicated on Figure 2. As $\alpha_{0}$ and $W$ rise the demand schedule shifts to the right; as $\beta_{0}, S$ and $\rho$ rise the demand schedule shifts to the left.

If equations (5) do not apply and the supply schedule is infinitely elastic the contract equilibrium is determined at $b$ and $B_{0}$ of benefit is written into the contract. In this case the premium is $P_{0}^{\prime} B_{0}$. If instead equations (5) do apply and the supply schedule is upward sloping the contract equilibrium is determined at $a$ and $B_{1}$ of benefit is written into the contract. In this case the premium is $P_{1}^{\prime} B_{1}$.

A client on a higher wage will tend to demand more cover at a given price because he has more to insure. His $D$ schedule will tend to lie to the right of that shown on fig. 2 . However, the supply schedule that he faces will also tend to lie to the right of $P_{0}^{\prime} S$ because a given quantity of $B$ induces less moral hazard. The equilibrium value for $B$ must rise relative to $B_{1}$ and it is likely (though not essential) that the unit price of benefit will rise. If $\alpha_{0}$ rises the $D$ schedule shifts to the right and the $P_{0}^{\prime} S$ schedule shifts to the left. The premium must rise but the amount of cover that is purchased may rise or fall. A similar line of reasoning applies if $\beta_{0}$ falls.

\section{Illustrations}

Fortunately, empirical work by Stephen Nickell and his colleagues may be used to generate estimates for the $\alpha$ s and $\beta$ s that are necessary for calculating the competitive premia for various risk classes. Details of this methodology may be found in Beenstock and Brasse (1984, cap. 4). Inflow rates $(\alpha)$ are based on Stern (1982) for 1978 while outflow rates $(\beta)$ are based on Nickell (1979). In the latter case we convert the mean duration of unemployment spells into $\beta$ values which are then scaled upwards to reflect the higher levels of unemployment in 1978 than in 1972 to which Nickell's study refers. This implies that the premia refer to information relevant to 1978 .

Using a real discount rate $(\rho)$ of 2 percent per year values of $P$ are then calculated using equation (4), setting $T_{1}=1$ (month), $T_{2}=\infty$ and $B=£ 1$. Some illustrative results are plotted on fig. 3 which sets risk categories in terms of age, marital status and numbers of children for men. On the whole the young and the old pay higher premiums because their $\alpha$ s are higher and their $\beta$ s are lower. Also married men are less of a risk than single men, hence their premiums are lower. Other cases may be found in Beenstock and Brasse. 
Figure 3. Illustrations of premium rates (1978)

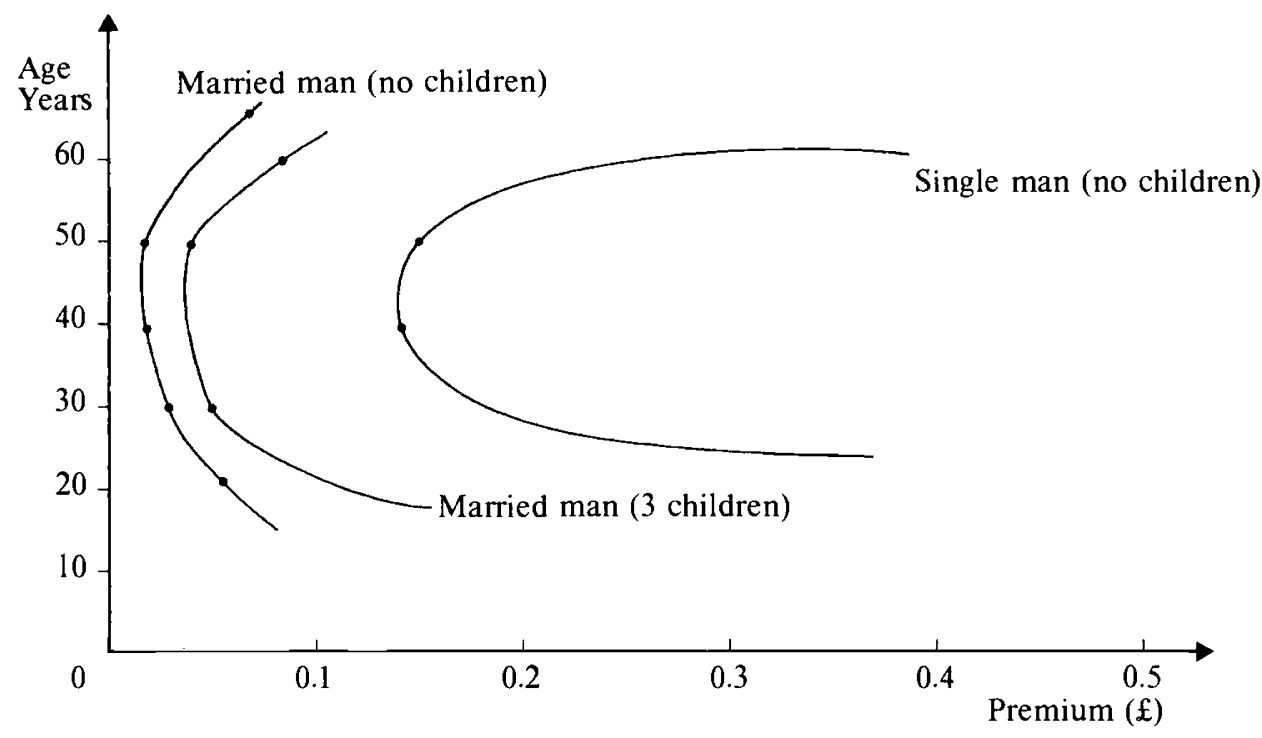

It turns out that there is no significant correlation between wage rates and competitive premium rates $(P)$ in the U.K. Therefore, it is not the case that those who would be required to pay relatively high premia because of their relatively large unemployment risks are those who can least afford it. This suggests that unemployment insurance is not as redistributive as Professor Malinvaud suggests - if it were those on lower wages would have had to pay higher premiums under competitive conditions.

The data on fig. 3 assume that the replacement ratio $(R)$ is 70 percent. Nickell (1979) argues that as $R$ rises moral hazard increases and the duration of unemployment lengthens. This in turn implies that the outflow rate from unemployment falls in which case via equation (4) the competitive premium should rise. This is illustrated on table 1 with respect to a 40 year old married man with 3 children. In case A the replacement ratio is 70 percent and the premium works out to be $3.6 \mathrm{p}$. When the replacement ratio is raised to 100 percent in case $B$, Nickell's model implies that $\beta$ falls from 0.19 to 0.123 . Most probably $\alpha$ will rise too but in the absence of empirical estimates $\alpha$ is assumed to be constant. The lower value of $\beta$ raises $P$ to $5.6 \mathrm{p}$. In this way it is possible to price moral hazard.

Table 1. Effects of moral hazard

\begin{tabular}{|c|c|c|c|c|}
\hline & $\alpha$ & $\beta$ & $R$ & $P(£)$ \\
\hline$A$ & 0.007 & 0.19 & 0.7 & 0.036 \\
$B$ & 0.007 & 0.123 & 1.0 & 0.056 \\
\hline
\end{tabular}




\section{Conclusion}

The above comments are intended to be suggestive; they certainly do not provide a firm basis for reform which would require considerably more research. On the other hand, they suggest that to Professor Malinvaud's criticisms of the literature on unemployment insurance we may add a further dimension. This dimension begs the question whether proper actuarial pricing principles cannot also be applied to unemployment insurance.

\section{REFERENCES}

BAILY, M. N. : "Unemployment Insurance as Insurance for Workers", Industrial and Labour Relations Review, July 1977.

BEENSTOCK, M., and BRASSE, V.: Market Pricing of Unemployment Insurance, Institute for Economic Affairs, London, forthcoming.

FLEMMING, J.: " Aspects of Optimal Unemployment Insurance ", Journal of Public Economics, pp. 403-425, 1978.

HARRIS, J., and TODARO, M. P. : “ Migration, Unemployment and Development : a Two Sector Analysis ", American Economic Review, March 1970.

KRAUS, A., and ROSS, S. A.: “ The Determination of Fair Profits for the Property Liability Insurance Firm ", Journal of Finance, 1982.

NICKELL, S. : "Estimating the Probability of Leaving Unemployment ", Econometrica, September 1979.

SAMPSON, A. A. : “Optimal Redundancy Compensation ”, Review' of Econornic Studies, 1979.

SHAVELL, S., and WEISS, L. : “ The Optimal Payment of Unemployment Insurance Benefits over Time ", Journal of Political Economy, Vol. 87, No. 61, pp. 1347-1362, 1979.

STERN, J.: “Unemployment Inflow Rates for Autumn 1978”, Centre for Labour Economics, discussion paper No. 129, LSE, June 1982. 